\title{
PARTICIPACÃO DO ENFERMEIF:O DO TRABALHO NO PLANEJAMENTO E IMPLANTAÇÃO DE UM CENTRO DE SAÚDE PARA A COMUNIDADE UNIVERSITÁRIA
}

\begin{abstract}
RESUMO - É feita revisão das recomendações sobre os serviços de saúde no trabalho e relato da experiência no planejamento e implantação de Centro de Saúde segundo as necessidades de saúde da população conhecidas e estimadas, sendo uma oportunidade do enfermeiro exercer funções além das tradicionalmente assumidas em Enfermagem Ocupacional.
\end{abstract}

\begin{abstract}
A revision is made of recommendations about health services at work. An experience in planning and implementing an out-patient clinic in then narrated, taking into account know and estimated health needs of the population. It is seen as an opportunity for the nurse to assume a role beyond the traditionally assumed in Occupational Health.
\end{abstract}

\section{INTRODUÇÃO}

- “O estudo epidemiológico da distribuição da saúdedoença em trabalhadores enquanto grupo, comunidade ou classe permite descrever com suficiente nitidez que a ocupação ou trabalho podem comportar-se como importantes determinantes na produção e distribuição da saúde-doença" (MENDES, 1986).

A nível mundial cabe à Organização Internacional do Trabalho (OIT), órgão ligado à Organização das Nações Unidas, definir as diretrizes em questões relativas ao trabalho, inclusive sua relação com a saúde, tendo por subsídio amplas discussões entre seus países membros, de forma tripartite (governos, empregados e trabalhadores?.

A primeira Recomendação da OIT em relação à Organização de Serviços de Saúde Ccupacional é a de número 112, de 1959, que se intitula "Serviços de Medi- cina do Trabalho nos locais de Trabalho" (OIT, 1959). Nela são caracterizadas as funções de um serviço deste tipo e a ele é atribuída a responsabilidade pela saúde do trabalhador.

Em 1985 são aprovados o Convênio no 161 e a Recomendação n? 171, sobre "Serviços de Saúde no Trabalho" (OIT, 1985) expressam as tendências atuais de, por exemplo, abordar a saúde total do trabalhador, não se restringindo aos problemas estritamente ocupacional.

Percebe-se um "grande" avanço entre a Recomendação de 1959 e a de 1985, pois a última atribui à empresa a responsabilidade pelas condições de trabalho, recomenda a participação ativa dos trabalhadores nas questões relativas à Saúde e, recomenda a necessidade de haver uma equipe multidisciplinar nos serviços de saúde nos locais de trabalho.

\footnotetext{
* Enfermeira do Trabalho do Centro de Saúde da Comunidade da UNICAMP - Campinas - SP., e aluna do Curso de Especialização em Saúde Pública, do Depto. de Medicina Preventiva e Social da FCM/UNICAMP

** Enfermeira do Trabalho e de Saúde Pública. Dir etora do Serviço de Enfermagem do Centro de Saúde da Comunidade da UNICAMP - Campinas - SP., e aluna do Curso de Mestrado em Saúde Ambiental da Faculdade de Saúde Pública - USP.
} 
No Brasil, "na década de 70, a observação das assustadoras estatísticas de acidentes de trabalho, agora coletados e analisados a nível nacional (...) leva o Governo Federal a(...) regulamentar a obrigatoriedade dos Serviços de Segurança e de Medicina do Trabalho nas empresas acima de determinado porte e grau de risco (Portarias n. 3237, de 21/07/72; no 3442, de 23/12/74; 3460, de 31/12/75; no 3214, de 08/06/78)" (MENDES et alii 1984).

Desde a última legislação até o momento atual, podemos observar alguns aspectos em relação ao impacto dos Serviços Especializados em Segurança e Medicina do Trabalho (SESMT) sobre a saúde dos trabalhadores.

Observamos, em primeiro lugar, que os SESMT apresentam uma cobertura insuficiente, pois a obrigatoriedade de sua existência acontece na maioria das empresas com mais de 500 funcionários (dependendo do grau de risco), quando sabemos que " $98 \%$ de todos os estabelecimentos de trabalho e, no mínimo, $65 \%$ da força de trabalho empregada estão a descoberta (...) (MENDES 1986). Além disso, várias outras categorias não estão incluídas nesta estatística: trabalhadores agrícolas, subempregados, empregados do setor informal e outros.

Outro ponto a ser levado em consideração é a qualidade dos serviços existentes pois "é forçoso reconhecer que a obsessão pelo lucro, que perceptivelmente ou imperceptivelmente permeia toda organização empresarial capitalista, acaba por contagiar o Serviço Médico, e não raras vezes manifesta-se em procedimentos de Medicina do Trabalho eticamente inaceitáveis" (MENDES 1986). Certamente esta afirmação é válida também para os outros membros da equipe de Saúde Ocupacional.

Diante da realidade apresentada, deparamos-nos no momento com perspectivas de mudanças, a partir das recomendaçẽos internacionais já citadas, com a realização no ano passado da 8a. Conferência Nacional de Saúde e da 1a. Conferência Nacional de Saúde do Trabalhador, e com as perspectivas da Reforma Sanitária (CONFERÊNCIA..., 1986).

\section{DESENVOLVIMENTO}

É dentro deste contexto que julgamos importante relatar nossa experiência na criação de um Serviço de Saúde para a comunidade de uma universidade, no sentido de que ele é uma proposta alternativa em que não se buscou somente abedecer a exigências legais mas, sim, atender as necessidades de saúde conhecidas e estimadas da comunidade.

Faz-se necessário lembrar o papel da universidade como modelo, seja em relação ao ensino, à pesquisa ou à assistência.

Nesta perspectiva, em relação ao ensino é importante ressaltar que "quando o corpo discente é expos- to , durante a vida acadêmica, a situações reconhecidas como sistemas de produção inseguras, nos laboratórios, of icinas e edificações, onde existem instalações deficientes, improvisações e métodos de trabalho incompatíveis com o risco inerente aos insumos utilizados, ele aceita o quadro como normal ou até correto" (GUALBERTO FILHO, 1986).

A universidade em questão “... se apresenta como um campo fértil em situações originais onde NADA existe em escala industrial, porém TUDO de imaginável se faz presente. Não há um campo específico para o qual ela se volta mas sim, ela está em todos: da agricultura às artes, da metalurgia aos esportes, da química à filosofia. E, uma gama extensa de experimentos envolvendo compostos, materiais e equipamentos nem bem citados em legislação alguma, por simples falta de conhecimento são aqui desenvolvidos (KAZAMA et alii, 1982).

O SESMT desta universidade teve em 1973 as primeiras sementes para sua implantação, mas apenas em 1981 foi oficialmente criado.

Quando da entrada da primeira de nós neste serviço em 1985, o mesmo fazia atendimentos apenas ocupacionais (exames de saúde pré-admissionais e periódicas e análise de pedidos de insalubridade e periculosidade) e a composição da equipe se resumia à prevista pela legislação (Norma Regulamentadora $n+4$ da Portaria 3214 do Ministério do Trabalho) (BRASIL, 1985).

No final do mesmo ano houve mudança na coordenação do serviço, tendo sido realizado um inquérito preliminar para conhecer os riscos ocupacionais e as necessidades de saúde da população, bem como estudos sobre as possibilidades de atendimento mais racional e adequado. Participaram vários profissionais de diferentes vinculações, e coube à enfermeira do trabalho os temas: "Instalações e Equipamentos necessários para o Ambulatório da um SESMT atuante" e "Estudo para a Implantação de um Programa de identificação e Acompanhamento de Funcionários com Problemas de Saúde (crônicos)".

Nestas propostas já havia sugestão de um número maior de enfermeiras do trabalho do que o previsto em lei e havia a previsão de que estas atuassem diretamente com o cliente, numa área de atendimento aos problemas agudos, junto aos portadores de doenças crõnicas através de grupos educativos e consulta de enfermagem, além da ampliação das atividades ocupacionais a serem realizadas, como visitas aos locais de trabalho, levantamento de problemas de saúde ligados ou não ao trabalho e educação em relação à saúde e trabalho.

Todos os estudos componentes do inquérito foram discutidos e a partir deles criado um documento único, com as propostas a serem implementadas incluindo o esboço de planta física de um prédio de três andares e o dimensionamento inicial dos recursos humanos necessários. 
Para o desenvolvimento desta proposta, foi contratada uma enfermeira do grupo, agora num órgão reativado da universidade, que englobou o SESMT e outros serviços de saúde prestados à comunidade que foram integrados, tendo a mesma procedido o levantamento dos materiais, dos serviços existentes seguindose a previsão e seleção para aquisição dos móveis e equipamentos necessários. Concomitantemente, foi reavaliada a planta física das diversas áreas em função do redimensionamento de recursos materiais e humanos, procedendo-se orientação e acompanhamento da execução da planta e a relação dos profissionais.

Num espaço de quatro meses o Centro de Saúde iniciou seu funcionamento contando com ambulatórios de pronto atendimento e clínica geral, de assistência à mulher, de saúde ocupacional e odontológica, visando a cobertura de aproximadamente vinte mil pessoas, entre funcionários, alunos e docentes.

Dentre vários serviços, foi criado o Serviço de Enfermagem, que englobava a assistência no prontoatendimento, na clínica geral e na saúde ocupacional, sendo distribuídas entre as sete enfermeiras, as áreas (assistencial e ocupacional) e os programas (alcoolismo, diabetes, epilepsia, hipertensão arterial e lombalgia).

Entre as dificuldades encontradas, salientamos algumas:

- A dificuldade em conseguir a ampliação do número de enfermeiras do trabalho, talvez pela restrita atuação deste profissional fora dos SESMTs das empresas em que sua presença é legalmente exigida.

- Não houve "modelo" no qual pudéssemos buscar subsídios pela característica pioneira do serviço (é o único com essas dimensões de que temos conhecimento) e por se tratar de assistência à saúde em comunidade bem delimitada.

- Nesta perspectiva, também o planejamento em relação a materiais, equipamentos e planta física foram difíceis, pois a bibliografia existente se refere basicamente a hospitais, e a centros de saúde de atendimento essencialmente materno-infantil.

- Em relação ao trabalho em equipe multiprofissional, muitas vezes não houve coincidência de objetivos e expectativas de um profissional em relação ao outro.

- Em relaçâo à atuação das enfermeiras, algumas apresentaram dificuldades em definir seu papel e espaço nas atividades desenvolvidas no serviço, tendo sua atuação bastante diluída na equipe multiprofissional. Isso gerou, uma retração da atuação da enfermeira em uma das áreas e em alguns programas.

\section{CONCLUSÃO}

Tendo em vista a característica inovadora de nosso trabalho, acreditamos na importância de sua divulgação, no sentido de que esta experiência possa ser utilizada por outros colegas.
Um outro aspecto a salientar é o de que sendo a Enfermagem do Trabalho uma especialidade recente, houve dificuldades no planejamento inicial em se conseguir um espaço para a atuação deste profissionale, quando da ampliação do número de vagas, outras dificuldades surgiram em relação à percepção do enfermeiro quanto a seu espaço e competência.

Nas palavras de ANGERAMI et alii (1983), "A formação da competência do enfermeiro inicia-se no sentido formal de enfermagem, que corresponde ao curso de graduação. Esta formação tem sido discutida e questionada, especialmente no que diz respeito à adequação do ensino à realidade, ficando o aparelho formador dividido entre a formação de pessoal para atender às necessidades da população e/ou mercado de trabalho da saúde"'.

Assim, cremos ser necessário uma reflexão acerca da definição do "espaço" de atuação do enfermeiro, em especial, a nível ambulatorial, tendo em vista sua formação centrada na atenção terciária.

BULHÕES ressalta que "em enfermagem do trabalho, então, a situação é às vezes ainda mais crítica. Distanciada de seus pares, por força do serviço que presta esta modalidade de enfermagem freqüentemente tem incluído em suas rotinas de trabalho, atividades bastante afastadas de sua obrigação principal, que é cuidar, no seu nível e em sua área, da saúde dos trabalhadores".

Acreditamos, conforme ANGERAMI et alii (1983), "é importante que os profissionais de enfermagem engajados e preocupados em assumir o seu lugar ou espaço que lhe pertence, assumam uma postura crítica e questionem costantemente sua práxis e verifiquem se estão inseridos... na praxis criadora, a qual permite enfrentar novas situações criando constantemente novas soluções. A práxis criadora é revolucionária, própria de uma consciência inquieta, aberta e receptiva e reflexões e experimentações. Não se encastela em si mesmo, após haver elevado o produto ideal, mas sim, 0 vai transformarıdo de acordo com as exigências externas com os meios e intrumentos que dispõem". (ANGERAMI et alii, 1983).

\section{REFERÊNCIAS BIBLIOGRÁFICAS}

1 ANGERAMI, E.L.S et alii. De como o enfermeiro está inserido no seu espaço. Revista Brasileira de Enf ermagem, Brasília, 36 (2): 123-9, abr.jun. 1983.

2 BRASIL Ministério do Trabalho. Portaria no 33, de 27 de out. de 1983. Altera as Normas Regulamentadoras, NR-4 e NR-5, aprovadas pela Portaria no 3214 , de 08 de jun. de 1978. In: Segurança e medicina do trabalho. 9. ed. São Paulo, Atlas, 1985. p. 23-64, 305 (Manuais de Legislação Atlas, 16).

3 BULHÕES, I. Enfermagem do Trabalho.. Rio de Janeiro, IDEAS, 1986. V. 2

4 CONFERÊNCIA NACIONAL DE SAÚDE DOS TRABALHADORES, 1, Brasília, Relatório. 8 p.

5 GUALBERTO FILHO, A. As condições de trabalho na universidade e seus reflexos na formação do aluno e na sociedade. Revista Brasileira Saúde Ocupacional, São Paulo, 43 (43): 15-6, jan./mar. 1986. 
6 KAZAWA, K.H. et alii - A criação de serviço especializado em segurança e medicina do trabalho-UNICAMP. In: JORNADA BRASILEIRA DE ECOLOGIA HUMANA, 3., Campinas, 1982.

7 MENDES, R. Doutrina e prática da integração da saúde ocupacional no setor saúde: contribuição para a definição de uma política. São Paulo, 1986 , 384 p. Faculdade de Saúde Pública USP (Tese de Livre-Docência).

8 MENDES, R. et alii - Medicina do trabalho no Brasil - Análise da situação atual e tendências. Temas IMESC Soc. Dir. Saúde, São Paulo, 1 (2): 83-92, 1984.

9 ORGANIZAÇÃO INTERNACIONAL DO TRABALHO. Recomendação n? 112(1959). Sobre os serviços de medicina do trabalho nos locais de trabalho, 6 p. mimeogr.

10 ORGANIZACIÓN INTERNACIONAL DEL TRABAJO - Texto de la recomendación sobre servicios de salud en el trabajo. Genebra, 1985. (Actas provisionales de la Conferencia Internacional del trabajo, 71a. Reunión, 28 B/ 1-2813/7). 